\title{
Clinical Subgroups in Bilateral Meniere Disease
}

\author{
Lidia Frejo ${ }^{1}$, Andres Soto-Varela², Sofía Santos-Perez², Ismael Aran, \\ Angel Batuecas-Caletrio ${ }^{4}$, Vanesa Perez-Guillen ${ }^{5}$, Herminio Perez-Garrigues ${ }^{5}$, \\ Jesus Fraile ${ }^{6}$, Eduardo Martin-Sanz 7 , Maria C. Tapia ${ }^{8}$, Gabriel Trinidad ${ }^{9}$, \\ Ana María García-Arumi ${ }^{10}$, Rocío González-Aguado ${ }^{11}$, Juan M. Espinosa-Sanchez ${ }^{1,12}$, \\ Pedro Marques ${ }^{13}$, Paz Perez ${ }^{14}$, Jesus Benitez ${ }^{15}$ and Jose A. Lopez-Escamez ${ }^{1,16 *}$ On Behalf \\ of the Meniere's Disease Consortium (MeDiC)
}

\section{OPEN ACCESS}

Edited by:

Herman Kingma,

Maastricht University Medical Center,

Netherlands

Reviewed by:

Maurizio Barbara,

Sapienza University, Italy

Hong Ju Park,

Asan Medical Center, University of

Ulsan, South Korea

*Correspondence:

Jose A. Lopez-Escamez antonio.lopezescamez@genyo.es

Specialty section: This article was submitted to Neuro-otology,

a section of the journal

Frontiers in Neurology

Received: 09 May 2016 Accepted: 07 October 2016 Published: 24 October 2016

Citation:

Frejo L, Soto-Varela A,

Santos-Perez S, Aran I, BatuecasCaletrio A, Perez-Guillen V,

Perez-Garrigues H, Fraile J, Martin-Sanz E, Tapia MC, Trinidad G,

García-Arumi AM, GonzálezAguado R, Espinosa-Sanchez JM, Marques $P$, Perez $P$, Benitez $J$ and Lopez-Escamez JA On Behalf of the

Meniere's Disease Consortium (MeDiC) (2016) Clinical Subgroups in

Bilateral Meniere Disease. Front. Neurol. 7:182. doi: 10.3389/fneur.2016.00182
'Otology and Neurotology Group CTS495, Department of Genomic Medicine - Centro de Genómica e Investigación Oncológica - Pfizer/Universidad de Granada/Junta de Andalucía (GENYO), Granada, Spain, ${ }^{2}$ Department of Otorhinolaryngology, Division of Otoneurology, Complexo Hospitalario Universitario, Santiago de Compostela, Spain, ${ }^{3}$ Department of Otolaryngology, Complexo Hospitalario de Pontevedra, Pontevedra, Spain, ${ }^{4}$ Department of Otolaryngology, Hospital Universitario Salamanca, Salamanca, Spain, ${ }^{5}$ Department of Otorhinolaryngology, Hospital Universitario La Fe, Valencia, Spain, ${ }^{6}$ Department of Otolaryngology, Hospital Miguel Servet, Zaragoza, Spain, ${ }^{7}$ Department of Otolaryngology, Hospital Universitario de Getafe, Getafe, Spain, ${ }^{8}$ Department of Otorhinolaryngology, Instituto Antolí Candela, Madrid, Spain, ${ }^{9}$ Department of Otorhinolaryngology, Division of Otoneurology, Complejo Hospitalario Badajoz, Badajoz, Spain, ${ }^{10}$ Department of Otorhinolaryngology, Hospital Universitario Vall d'Hebron, Barcelona, Spain, ${ }^{11}$ Department of Otorhinolaryngology, Hospital Universitario Marqués de Valdecilla, Santander, Cantabria, Spain, ${ }^{12}$ Department of Otorhinolaryngology, Hospital San Agustin, Linares, Jaen, Spain, ${ }^{13}$ Department of Otorhinolaryngology, Centro Hospitalar de São João, EPE, University of Porto Medical School, Porto, Portugal, ${ }^{14}$ Department of Otorhinolaryngology, Hospital Cabueñes, Gijón, Spain, ${ }^{15}$ Department of Otolaryngology, Hospital Universitario de Gran Canaria Dr. Negrin, Las Palmas, Spain, ${ }^{16}$ Department of Otolaryngology, Instituto de Investigación Biosanitaria ibs. GRANADA, Complejo Hospitalario Universidad de Granada (CHUGRA), Granada, Spain

Meniere disease (MD) is a heterogeneous clinical condition characterized by sensorineural hearing loss, episodic vestibular symptoms, and tinnitus associated with several comorbidities, such as migraine or autoimmune disorders (AD). The frequency of bilateral involvement may range from 5 to $50 \%$, and it depends on the duration of the disease. We have performed a two-step cluster analysis in 398 patients with bilateral MD (BMD) to identify the best predictors to define clinical subgroups with a potential different etiology to improve the phenotyping of BMD and to develop new treatments. We have defined five clinical variants in BMD. Group 1 is the most frequently found, includes $46 \%$ of patients, and is defined by metachronic hearing loss without migraine and without AD. Group 2 is found in $17 \%$ of patients, and it is defined by synchronic hearing loss without migraine or AD. Group 3, with $13 \%$ of patients, is characterized by familial MD, while group 4 , that includes $12 \%$ of patients, is associated by the presence of migraine in all cases. Group 5 is found in $11 \%$ of patients and is defined by AD. This approach can be helpful in selecting patients for genetic and clinical research. However, further studies will be required to improve the phenotyping in these clinical variants for a better understanding of the diverse etiological factors contributing to BMD.

Keywords: cluster analysis, vestibular disorders, hearing loss, tinnitus, Meniere's disease, migraine, autoimmune disorders, inner ear 


\section{INTRODUCTION}

Meniere's disease (MD) is a long-lasting disorder of the inner ear characterized by episodes of vertigo lasting from $20 \mathrm{~min}$ to hours, low-to-middle frequencies sensorineural hearing loss (SNHL, Table 1), tinnitus, and aural fullness (1). MD patients have phenotypic heterogeneity (2), and it is difficult to define the outcome of the disease in its early stages. Although the frequency of the spells of vertigo is typically greater during the earlier years (3-5), balance problems are observed during the course of the disease and might become severe if patients progress to a bilateral vestibular hypofunction $(6,7)$. Most of the patients start with SNHL in one ear, and it can appear in the other after several years (metachronic SNHL) (8), but a significant number of individuals show simultaneous SNHL (synchronic SNHL). Bilateral involvement is a major concern for patients because of the loss of vestibular function, and bilateral SNHL has a significant influence in the health-related quality of life in MD patients (9).

Several studies have reported contralateral ear involvement between 2 and $73 \%$ of cases, depending on the interval of follow-up and the diagnostic criteria used. However, if bilateral MD (BMD) was defined as the combination of clinical symptoms and audiometric tests, the frequency would be $2-47 \%$ (7). Some studies describe an interval of 5 years where the incidence was $10-35 \%(8,10-13)$, while in other studies, with a followup of 10 years or more, the frequency of BMD ranges from 20 (14-16) to $46 \%$ (17). However, more than 20 years of follow-up have also been described, and the incidence rate of bilaterality rises up to $47 \%$ (18-22). Although there is a great disparity in the percentage of individuals with bilateral involvement, most of the studies highlighted that the number of patients with contralateral ear involvement increased with the duration of the disease $(18,21,22)$.

Several comorbidities have been associated with MD, including autoimmune disorders and migraine. So, MD has been previously associated with several autoimmune diseases, such as systemic lupus erythematous, psoriasis, or rheumatoid arthritis $(6,23)$, and autoimmunity has been suggested as a potential cause in MD (24) relying on the results of proteomic studies achieved in small series of patients (24-26). However, high levels of circulating immune complexes were not found in most of the patients with MD (27).

\section{TABLE 1 | List of abbreviations.}

\begin{tabular}{ll}
\hline AAO-HNS & American Academy Otolaryngology - Head Neck Surgery \\
AD & Autoimmune disorders/disease \\
AIED & Autoimmune inner ear disorder \\
BMD & Bilateral Meniere disease \\
BMD type 1 & Metachronic hearing loss \\
BMD type 2 & Synchronic hearing loss \\
BMD type 3 & Familial Meniere disease \\
BMD type 4 & Meniere disease + migraine \\
BMD type 5 & Meniere disease + autoimmune disease \\
FMD & Familial Meniere disease \\
MD & Meniere disease \\
MRI & Magnetic resonance imaging \\
RCT & Randomized clinical trials \\
SNHL & Sensorineural hearing loss \\
SMD & Sporadic Meniere disease
\end{tabular}

Furthermore, autoimmune mechanisms seem to be associated with the pathogenesis of some types of SNHL $(28,29)$, such as sudden SNHL (30), promptly progressive bilateral SNHL (31), and MD (32-34). Additionally, several genes of the immune system have been studied in case-control studies (35-38), but they have not been replicated. Moreover, some data suggest that allelic variants of MICA and TLR10 genes, involved in the innate immune response, may influence the susceptibility and time course of hearing loss of MD in European population $(39,40)$.

Migraine has been consistently found to be more common in MD than in the general population in case-control studies (41), but it is not clear if this association has any role in the pathophysiology of MD. Vestibular migraine (VM), the condition of episodic vestibular symptoms linked to migraine spectrum (42), may occur in some patients concomitantly with MD (43).

Genetic factors are probably relevant in a subset of patients with MD. So, familial MD was first described in 1949 by Brown (44), and many studies have described familial cases of MD (45). The genetic contribution to MD has been recently reviewed $(46,47)$, and there are several evidences to support a genetic origin in MD. These evidences include (a) the prevalence is higher in European descent population than in Asian (48) or African populations (49) and (b) familiar aggregation has been observed in 6\% in South Korea and 8-9\% in Spain (2), being

TABLE 2 | Clinical phenotype in sporadic and familial Meniere disease with at least 5 years since the onset of the disease.

\begin{tabular}{|c|c|c|c|}
\hline Variables & FMD $(n=52)$ & SMD $(n=258)$ & $p$-value \\
\hline Age, mean (SD) & $55.5(12.7)$ & $61.5(11.1)$ & 0.001 \\
\hline Gender (\% women) & $34(65.4)$ & 147 (57.0) & 0.28 \\
\hline Age of onset (SD) & 39 (12.9) & $44.8(13.1)$ & 0.003 \\
\hline Age of onset $\leq 40, n(\%)$ & $28(53.8)$ & $96(37.2)$ & 0.03 \\
\hline $\begin{array}{l}\text { Time course (years), } \\
\text { mean (SD) }\end{array}$ & $16.3(8.7)$ & $16.3(9.4)$ & 0.96 \\
\hline Synchronic, $n(\%)$ & $11(21.6)$ & 72 (27.9) & 0.39 \\
\hline Metachronic, $n(\%)$ & $40(78.4)$ & $186(72.1)$ & \\
\hline $\begin{array}{l}\text { Hearing loss at diagnosis, } \\
\text { mean (SD) }\end{array}$ & $51.9(15.5)$ & $56.6(17.8)$ & 0.092 \\
\hline Headache, $n(\%)$ & $23(44.2)$ & $92(36.1)$ & 0.27 \\
\hline Migraine, $n(\%)$ & $13(25.0)$ & $44(17.3)$ & 0.24 \\
\hline Rheumatoid history, $n$ (\%) & $10(20.4)$ & $25(9.8)$ & 0.048 \\
\hline \multicolumn{4}{|l|}{ Hearing stage, $n(\%)$} \\
\hline 1 & $0(0.0)$ & $4(1.6)$ & 0.58 \\
\hline 2 & $9(17.6)$ & $35(13.6)$ & \\
\hline 3 & $28(54.9)$ & $131(51.0)$ & \\
\hline 4 & $14(27.5)$ & $87(33.9)$ & \\
\hline \multicolumn{4}{|l|}{ Cardiovascular risk } \\
\hline High blood pressure, $n(\%)$ & $13(26.5)$ & $93(39.7)$ & 0.1 \\
\hline Dyslipidemia, $n(\%)$ & $21(42.0)$ & $111(47.6)$ & 0.53 \\
\hline Type 2 diabetes, $n(\%)$ & $12(24.0)$ & $41(17.4)$ & 0.32 \\
\hline Smoking, $n(\%)$ & $15(30)$ & $53(21.5)$ & 0.2 \\
\hline Tumarkin crisis, $n(\%)$ & $17(35.4)$ & $63(25.5)$ & 0.16 \\
\hline \multicolumn{4}{|l|}{ Functional Scale, $n$ (\%) } \\
\hline 1 & $9(17.6)$ & $53(21.3)$ & 0.81 \\
\hline 2 & $15(29.4)$ & $71(28.5)$ & \\
\hline 3 & $10(19.6)$ & $58(23.3)$ & \\
\hline 4 & $7(13.7)$ & $35(14.1)$ & \\
\hline 5 & $7(13.7)$ & $25(10.0)$ & \\
\hline 6 & $3(5.9)$ & $7(2.8)$ & \\
\hline
\end{tabular}

$S M D$, sporadic Meniere disease; FMD, familial Meniere disease.

Significant $p$ values in bold. 


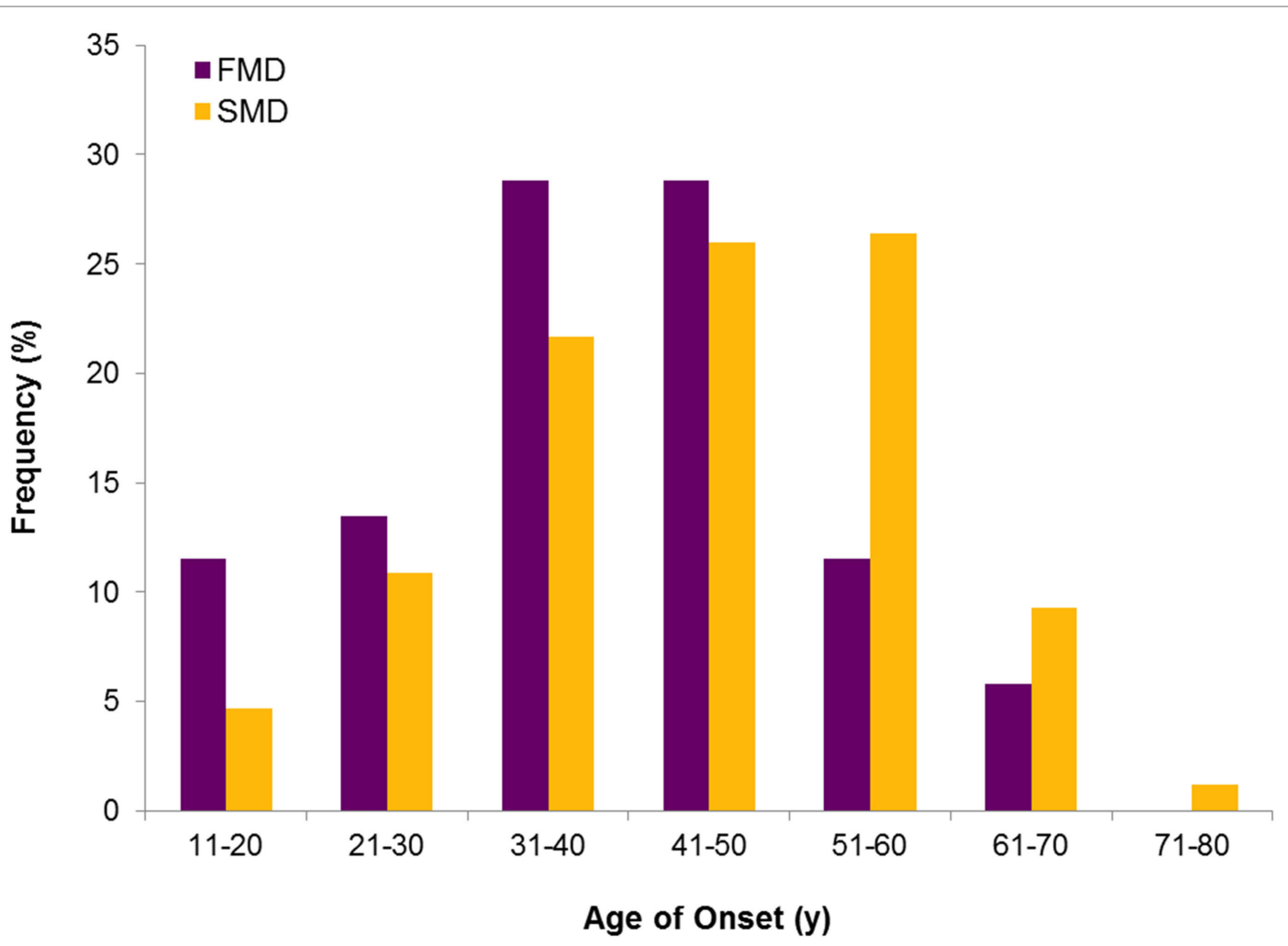

FIGURE 1 | Age of onset in bilateral Meniere disease. Distribution of frequencies in familial and sporadic cases shows an earlier onset in FMD.

TABLE 3 | Autoimmune diseases and other rheumatoid conditions observed in patients with bilateral Meniere disease.

\begin{tabular}{lr}
\hline Autoimmune diseases & N \\
\hline Rheumatoid arthritis & 10 \\
Fibromyalgia & 6 \\
Arthrosis & 5 \\
Ankylosing spondylitis & 5 \\
Psoriasis & 4 \\
Hypothyroidism & 3 \\
Sjogren syndrome & 3 \\
Type 1 diabetes & 2 \\
Rosacea & 2 \\
Graves-Basedow disease & 2 \\
Systemic lupus erythematous & 2 \\
Psoriatic arthritis & 1 \\
Autoimmune inner ear disease & 1 \\
Polymyalgia rheumatica & 1 \\
Inflammatory bowel disease & 1 \\
Cogan syndrome & 1 \\
Hip synovitis & 1 \\
Carpal tunnel syndrome & 1 \\
Undetermined & 1
\end{tabular}

DTNA and FAM136A genes involved in autosomal dominant familial MD (50).

The aim of this study is to describe the phenotype of patients with $\mathrm{BMD}$, including comorbidities such as autoimmune diseases or familial aggregation, and to perform a cluster analysis to identify clinical variants in BMD.

\section{MATERIALS AND METHODS}

\section{Subjects}

A multicenter, cross-sectional retrospective study was designed, including patients with BMD diagnosed and tracked by the Meniere's Disease Consortium. For this, the clinical records of a total of 405 patients diagnosed with definite BMD from 16 clinical centers in Spain and Portugal were reviewed in March 2016. MD diagnosis was established according to the diagnostic scale of the American Academy of Otolaryngology Head and Neck Surgery (AAO-HNS) (51). Familial MD (FMD) was defined if at least another relative (first or second degree) fulfilled all the criteria of definite or probable $\mathrm{MD}$, according to the criteria established by the Barany Society International Classification for Vestibular Disorders (1). Patients with unilateral MD or bilateral BMD with less than 5 years of evolution were excluded of the study. Seven patients were excluded because of inconsistent data. This study was approved by the Institutional Review Board for Clinical Research (PI-13-1242).

Every patient underwent a complete neuro-otological evaluation, including a pure-tone audiometry, an otoscopy, nystagmus examination, and a caloric testing. A brain MRI was performed to exclude any other possible cause of neurological symptoms. Patients with simultaneous SNHL in both ears were considered to have synchronic SNHL, while metachronic SNHL was considered if an interval longer than 1 month between the first and the second ear was observed. 
TABLE 4 | Clinical features of sporadic and familial bilateral Meniere disease stratified by the presence of autoimmune disease (AD).

\begin{tabular}{|c|c|c|c|c|c|c|}
\hline \multirow[t]{2}{*}{ Variables } & \multicolumn{3}{|c|}{ Sporadic MD } & \multicolumn{3}{|c|}{ Familial MD } \\
\hline & $A D+(n=25)$ & $A D-(n=230)$ & $p$-value & $A D+(n=10)$ & $A D-(n=39)$ & $p$-value \\
\hline Age, mean (SD) & $61.7(9.1)$ & $61.6(11.2)$ & 0.94 & $56.5(13.8)$ & $55(12.4)$ & 0.74 \\
\hline Gender (\% women) & $18(72.0)$ & $128(55.7)$ & 0.14 & $6(60.0)$ & $26(66.7)$ & 0.72 \\
\hline Age of onset (SD) & $43.4(11.0)$ & $45.2(13.2)$ & 0.5 & $35.9(12.3)$ & $40.5(13.0)$ & 0.31 \\
\hline Age of onset $\leq 40, n(\%)$ & $11(44.0)$ & $82(35.7)$ & 0.51 & $6(60.0)$ & $19(48.7)$ & 0.73 \\
\hline Time course (years), mean (SD) & $17.4(8.7)$ & $16.1(9.6)$ & 0.52 & $20.7(8.9)$ & $14(7.0)$ & 0.01 \\
\hline Hearing loss at diagnosis, mean (SD) & $57.5(18.3)$ & $56.7(17.8)$ & 0.83 & $52.3(15.2)$ & $52(15.9)$ & 0.96 \\
\hline Headache, $n(\%)$ & $15(62.5)$ & 77 (33.5) & 0.007 & $8(80.0)$ & $14(35.9)$ & 0.03 \\
\hline Migraine, $n(\%)$ & 8 (33.3) & $36(15.7)$ & 0.044 & $5(50.0)$ & $7(17.9)$ & 0.05 \\
\hline \multicolumn{7}{|l|}{ Hearing stage, $n(\%)$} \\
\hline 1 & $0(0.0)$ & $4(1.7)$ & 0.37 & $0(0.0)$ & $0(0.0)$ & 0.32 \\
\hline 2 & $5(20.0)$ & $30(13.1)$ & & $1(11.1)$ & $8(20.5)$ & \\
\hline 3 & $9(36.0)$ & $119(52.0)$ & & $4(44.4)$ & $23(59.0)$ & \\
\hline 4 & $11(44.0)$ & 76 (33.2) & & $4(44.4)$ & 8 (20.5) & \\
\hline \multicolumn{7}{|l|}{ Cardiovascular risk factors } \\
\hline High blood pressure, $n(\%)$ & $13(59.1)$ & $80(37.7)$ & 0.07 & $2(20.0)$ & $10(27.0)$ & 1 \\
\hline Dyslipidemia, $n(\%)$ & $12(50.0)$ & 97 (46.9) & 0.83 & $4(40.0)$ & $16(42.1)$ & 1 \\
\hline Type 2 diabetes, $n$ (\%) & 8 (33.3) & $33(15.8)$ & 0.046 & $5(50.0)$ & 7 (18.4) & 0.09 \\
\hline Smoking, $n(\%)$ & $6(28.6)$ & $47(21.0)$ & 0.41 & $3(30.0)$ & $12(30.8)$ & 1 \\
\hline Tumarkin crisis, $n$ (\%) & $6(27.3)$ & 57 (25.3) & 0.8 & $5(50.0)$ & $12(32.4)$ & 0.46 \\
\hline \multicolumn{7}{|l|}{ Functional Scale, $n(\%)$} \\
\hline 1 & $4(17.4)$ & 48 (21.3) & 0.94 & $2(20.0)$ & 7 (17.9) & 0.007 \\
\hline 2 & $7(30.4)$ & $64(28.4)$ & & $4(40.0)$ & $11(28.2)$ & \\
\hline 3 & $6(26.1)$ & $52(23.1)$ & & $1(10.0)$ & 8 (20.5) & \\
\hline 4 & $2(8.7)$ & $33(14.7)$ & & $0(0.0)$ & $6(15.4)$ & \\
\hline 5 & $3(13.0)$ & $22(9.8)$ & & $0(0.0)$ & $7(17.9)$ & \\
\hline 6 & $1(4.3)$ & $6(2.7)$ & & $3(30.0)$ & $0(0.0)$ & \\
\hline
\end{tabular}

Significant $p$ values in bold.

Clinical variables studied were as follows: gender, duration of disease, age of onset, family history of $\mathrm{MD}$, hearing loss at diagnosis, hearing stage defined as four-tone average of 0.5 , 1,2 , and $3 \mathrm{kHz}$ according to the AAO-HNS criteria (stage 1, $\leq 25 \mathrm{~dB}$; stage 2, 26-40 dB; stage 3, 41-70 dB, and stage 4, $>70 \mathrm{~dB}$ ), type of headache (migraine, tension-type headache), history of autoimmune disease (AD), cardiovascular risk factors (high blood pressure, type 2 diabetes, dyslipidemia, and smoking), Tumarkin crisis, and the Functional Scale of the AAO-HNS.

\section{Statistical Analysis}

A descriptive statistical analysis was carried out using SPSS software v.22 (SPSS Inc., Chicago, IL, USA). Data are shown as means with their SDs. Quantitative variables were compared using Student's unpaired T-test. Qualitative variables were compared using crosstabs and Fisher's exact test. Nominal $p$-values $<0.05$ were considered statistically significant.

We carried out a two-step cluster analysis using log-likelihood distance measures, which can detect relationships within a complex dataset between patients with multiple distinct characteristics. It tries to identify homogenous groups of cases based on the distribution of some variables (input variables). The method identifies the groups by running pre-clustering first and then by using hierarchical methods to classify and to find the optimal number of clusters.

Initially, we selected variables showing differences between the clinical groups during the descriptive analysis to test its relevance as predictors of clusters. The procedure was iterated several times until we found the minimum number of homogenous clusters. The final cluster analysis was applied using the four following categorical variables: history of autoimmune disease, onset of hearing loss (synchronic/metachronic), FMD or sporadic cases, and migraine. The four variables included produced a silhouette of cohesion and division of 0.8 , indicative of good data partitioning. Two additional variables were added to the model: age of onset $<40$ years old and gender, although their contribution to refine the clustering was limited.

\section{RESULTS}

Three hundred ninety-eight patients with BMD were included in the study. There were 258 sporadic cases and 52 individuals with FMD (20\%). Although apparently there were no clinical differences in the phenotype between sporadic and familial cases, FMD had an earlier age of onset $(p=0.003)$ and a higher prevalence of autoimmune comorbidities (Table 2). So, the distribution of frequencies for the age of onset showed that the number of patients starting before 40 years old was significantly higher in the FMD (Figure 1). Table 3 lists the autoimmune comorbid conditions found, being rheumatoid arthritis the most common in our cohort.

The clinical features in patients with sporadic and FMD were stratified according to the presence or absence of autoimmune comorbidities. In the sporadic cases, headache and migraine were most commonly observed in patients with autoimmune background (62.5 and 33\%, respectively) compared with patients without autoimmune comorbidities (33 and 16\%), suggesting 
a potential association between migraine and autoimmunity in patients with sporadic BMD (Table 4).

We also compared patients according to the onset of hearing loss (Table 5). One hundred three (26\%) individuals developed simultaneous hearing loss in both ears (synchronic hearing loss, either symmetric or asymmetric), while 291 (73\%) patients started with hearing loss in one ear and developed

TABLE 5 | Clinical features in bilateral Meniere disease according to the onset of hearing loss.

\begin{tabular}{|c|c|c|c|}
\hline Variables & $\begin{array}{l}\text { Synchronic } \\
\qquad(n=103)\end{array}$ & $\begin{array}{c}\text { Metachronic } \\
(n=291)\end{array}$ & $p$-value \\
\hline Age, mean (SD) & $61(11.0)$ & $60.1(11.9)$ & 0.49 \\
\hline Gender (\% women) & $63(61.2)$ & $161(55.3)$ & 0.36 \\
\hline Age of onset (SD) & $46.1(12.8)$ & $43.5(13.2)$ & 0.07 \\
\hline Age of onset $\leq 40, n(\%)$ & $39(37.9)$ & $118(40.5)$ & 0.73 \\
\hline Time course (years), mean (SD) & $14.4(8.9)$ & $16.2(8.9)$ & 0.08 \\
\hline Family history, $n(\%)$ & 39 (39.8) & $119(43.0)$ & 0.64 \\
\hline FMD, $n(\%)$ & $11(13.3)$ & $40(17.7)$ & 0.39 \\
\hline $\begin{array}{l}\text { Hearing loss at diagnosis, } \\
\text { mean (SD) }\end{array}$ & $55.1(17.0)$ & $55.9(17.0)$ & 0.71 \\
\hline Headache, $n(\%)$ & $55(53.4)$ & $96(33.3)$ & 0.0004 \\
\hline Migraine, $n(\%)$ & $25(24.3)$ & $49(17.0)$ & 0.11 \\
\hline Rheumatoid history, $n$ (\%) & $15(15.0)$ & $35(12.2)$ & 0.49 \\
\hline \multicolumn{4}{|l|}{ Hearing stage, $n(\%)$} \\
\hline 1 & $1(1.0)$ & $6(2.1)$ & 0.004 \\
\hline 2 & $27(26.5)$ & $34(11.7)$ & \\
\hline 3 & $42(41.2)$ & $152(52.4)$ & \\
\hline 4 & $32(31.4)$ & $98(33.8)$ & \\
\hline \multicolumn{4}{|l|}{ Cardiovascular risk } \\
\hline High blood pressure, $n(\%)$ & $47(51.1)$ & 109 (39.9) & 0.068 \\
\hline Dyslipidemia, $n(\%)$ & $53(55.2)$ & $121(45.1)$ & 0.097 \\
\hline Type 2 diabetes, $n$ (\%) & $13(13.5)$ & $50(18.5)$ & 0.35 \\
\hline Smoking, $n(\%)$ & $22(21.8)$ & $68(24.5)$ & 0.68 \\
\hline Tumarkin crisis, $n$ (\%) & $24(25.8)$ & $69(24.9)$ & 0.89 \\
\hline \multicolumn{4}{|l|}{ Functional Scale, $n$ (\%) } \\
\hline 1 & $14(14.0)$ & $73(26.0)$ & 0.11 \\
\hline 2 & $29(29.0)$ & $77(27.4)$ & \\
\hline 3 & $26(26.0)$ & 55 (19.6) & \\
\hline 4 & $12(12.0)$ & $40(14.2)$ & \\
\hline 5 & $16(16.0)$ & $27(9.6)$ & \\
\hline 6 & $3(3.0)$ & 9 (3.2) & \\
\hline
\end{tabular}

Significant $p$ values in bold. the hearing loss in the contralateral ear (metachronic hearing loss). Figure 2 compares the distribution of frequencies for the age of onset in patients with synchronic or metachronic hearing loss. There were no clinical differences between them, but the occurrence of headache was most commonly observed in synchronic hearing loss $(p=0.0004)$, and the worst hearing stage was observed in patients with metachronic hearing loss $(p=0.004)$.

We performed cluster analysis to identify groups of patients with common clinical features in BMD. Figure 3 shows the size of the clusters, the relevance of predictors, and the contribution of each predictor to define the cluster. The best predictors for clustering were autoimmune history, FMD, migraine, and the onset of hearing loss (synchronic/metachronic). Ninety-five patients remained unclassified because of incomplete clinical data.

We have defined five clusters for BMD and ranked them according to its relative frequency (Figure 4). Cluster 1 is the most common, including $46.5 \%$ of patients, and it is defined by metachronic hearing loss without migraine, sporadic BMD, and no autoimmune history. Cluster $2(17.5 \%)$ includes patients with synchronic hearing loss, sporadic BMD, no migraine, and no autoimmune history. Cluster $3(12.9 \%)$ includes patients with FMD without migraine in $82 \%$ of patients. Cluster $4(11.9 \%)$ consists of patients with migraine and sporadic BMD. Cluster $5(11.2 \%)$ groups all patients with autoimmune comorbidities, being $71 \%$ sporadic and $29 \%$ FMD.

Table 6 shows the five groups found and the major clinical differences among the groups. Comparing the age of onset by groups, we observe that groups 3-5 have earlier onsets than groups 1 and $2(p=0.0003)$. The type of hearing loss, FMD, migraine, and autoimmune comorbidities strongly differ among groups, and these variables are the basis to assign a given patient to each cluster.

\section{DISCUSSION}

The diagnostic criteria for MD formulated by the Classification Committee of the Bárány Society state that bilateral involvement is determined by hearing loss defined in the audiogram
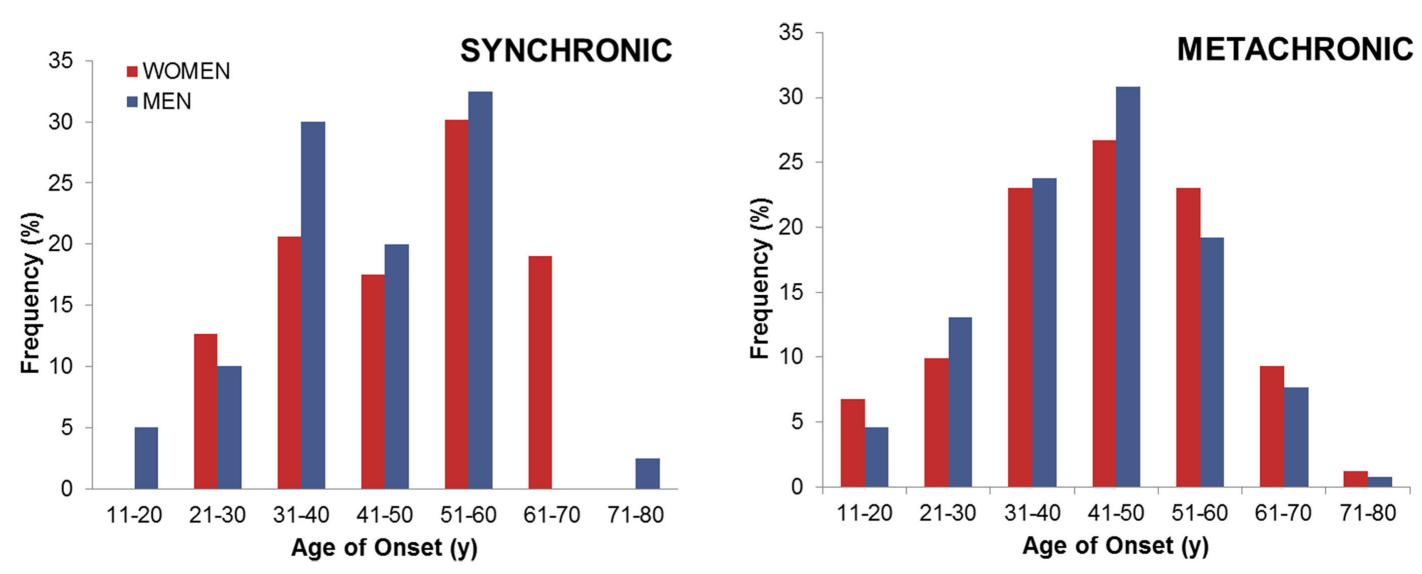

FIGURE 2 | Age of onset in bilateral Meniere disease according to the type of hearing loss observed. 
A Cluster Size

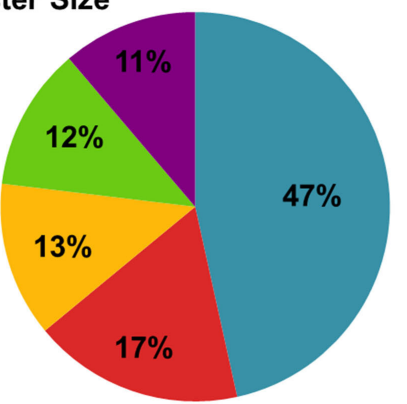

- BMD type 1 - BMD type 2 = BMD type $3 \backsim B M D$ type 4 - BMD type 5

B

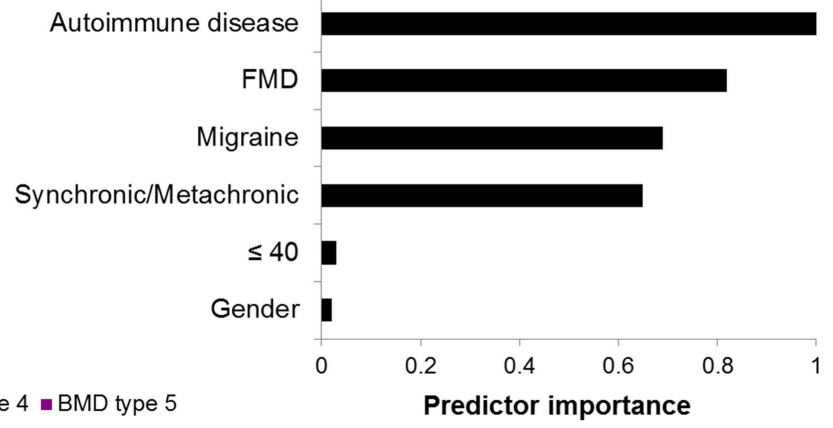

C

VARIABLES

BMD type 1 BMD type 2 BMD type 3 BMD type 4 BMD type 5

\begin{tabular}{|c|c|c|c|c|c|}
\hline $\mathrm{N},(\%)$ & $141(46.5)$ & $53(17.5)$ & $39(12.9)$ & $36(11.9)$ & $34(11.2)$ \\
\hline METACHRONIC HL (\%) & 100 & 0 & 82.1 & 77.8 & 61.8 \\
\hline SYNCHRONIC HL (\%) & 0 & 100 & 17.9 & 22.2 & 38.2 \\
\hline MIGRAINE (\%) & 0 & 0 & 17.9 & 100 & 38.2 \\
\hline AUTOIMMUNE DISEASE (\%) & 0 & 0 & 0 & 0 & 100 \\
\hline FMD (\%) & 0 & 0 & 100 & 0 & 29.4 \\
\hline SMD (\%) & 100 & 100 & 0 & 100 & 70.6 \\
\hline
\end{tabular}

FIGURE 3 | Summary of cluster analysis in bilateral Meniere disease (BMD). (A) Pie chart showing five groups or clinical variants in BMD. (B) Bar chart ranking the importance of predictors to define the groups. (C) Classification of BMD in five clinical variants according to its observed frequency and lead predictor: type 1, metachronic sensorineural hearing loss (SNHL); type 2, synchronic SNHL; type 3, familial Meniere disease (FMD); type 4, migraine; type 5, autoimmune disease.

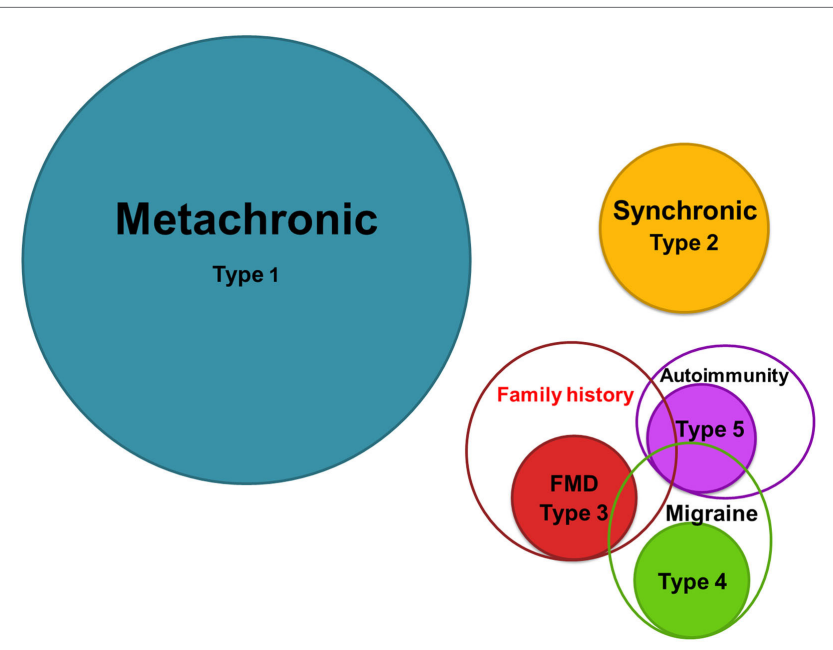

FIGURE 4 | Schematic diagram of the five subgroups in BMD. Circle areas are proportional to the frequency observed in each group.

(1). So, if the absolute thresholds for bone-conducted sound are $\geq 35 \mathrm{~dB}$ HL at each of two contiguous frequencies below $2000 \mathrm{~Hz}$ in both ears, and the patient has experienced $\geq 2$ episodes of spontaneous vertigo each lasting $20 \mathrm{~min}$ to $12 \mathrm{~h}$ associated with fluctuating aural symptoms, the diagnosis of definite BMD is established. The notes added to the definition also describe a second clinical variant when the patient develops simultaneous bilateral SNHL (symmetric or asymmetric) $(1,52)$, but no further clinical information was included in the definition.

Our study demonstrates that BMD is a heterogeneous disorder, and two-step cluster analysis is a very useful tool to define groups of patients with BMD according to four clinical predictors: FMD, autoimmune history, migraine, and the type of onset for hearing loss. We selected this method since it allows the inclusion of quantitative and categorical variables to define clusters (53).

We present a new classification for BMD in five groups of patients with potential etiological implications, which probably will improve the diagnostic workflow and the management of patients with BMD. Previous studies in patients with BMD were focused in the diagnosis by electrocochleography or MRI (54-56), but they did not consider the comorbidities commonly observed, such as migraine or AD in some cases. The phenotype of a patient with an episodic vestibular syndrome should not be limited to the description of the inner ear symptoms, skipping crucial information such as the familiar history of MD or migraine. Furthermore, the comorbidities of migraine or AD may explain the perception of $\mathrm{MD}$ as a continuum, which overlaps with migraine (57) or autoimmune inner ear disease $(1,58,59)$.

The most remarkable finding in our study is that the five groups of patients identified do not overlap themselves, and each of them has a set of features able to define the group.

Bilateral MD type 1 is the most common clinical variant, and it includes patients with MD in one ear (unilateral MD), and 
TABLE 6 | Clinical variants in bilateral Meniere disease (BMD) defined by two-step cluster analysis.

\begin{tabular}{|c|c|c|c|c|c|c|}
\hline Variables & $\begin{array}{c}\text { BMD type } 1 \\
(n=141)\end{array}$ & $\begin{array}{c}\text { BMD type } 2 \\
(n=53)\end{array}$ & $\begin{array}{c}\text { BMD type 3 | } \\
(n=39)\end{array}$ & $\begin{array}{c}\text { BMD type } 4 \\
(n=36)\end{array}$ & $\begin{array}{c}\text { BMD type } 5 \\
(n=34)\end{array}$ & $p$-value \\
\hline Group predictor & $\begin{array}{c}\text { Metachronic } \\
\text { SNHL }\end{array}$ & $\begin{array}{c}\text { Synchronic } \\
\text { SNHL }\end{array}$ & FMD & Migraine & AD & \\
\hline Age, mean (SD) & $63.3(11.0)$ & $62.4(9.5)$ & $54.7(13.2)$ & $54.1(11.5)$ & $59.7(11.1)$ & 0.00001 \\
\hline Gender (\% women) & $73(51.8)$ & $30(56.6)$ & $26(66.7)$ & 25 (69.4) & 24 (70.6) & 0.11 \\
\hline Age of onset (SD) & $46.4(13.1)$ & $47.9(12.0)$ & $40(14.5)$ & 37 (12.5) & $39.8(11.3)$ & 0.0003 \\
\hline Age of onset $\leq 40, n(\%)$ & $46(32.6)$ & 15 (28.3) & $19(48.7)$ & $21(58.3)$ & $16(47.1)$ & 0.011 \\
\hline Synchronic, $n(\%)$ & $0(0.0)$ & $53(100.0)$ & $7(17.9)$ & $8(22.2)$ & $13(38.2)$ & $3.39 \times 10^{-42}$ \\
\hline Metachronic, $n$ (\%) & $141(100.0)$ & $0(0.0)$ & $32(82.1)$ & $28(77.8)$ & $21(61.8)$ & \\
\hline Family history, $n$ (\%) & $18(12.8)$ & $7(13.2)$ & 39 (100.0) & $7(19.4)$ & $19(55.9)$ & $1.81 \times 10^{-27}$ \\
\hline FMD, $n(\%)$ & $0(0.0)$ & $0(0.0)$ & 39 (100.0) & $0(0.0)$ & $10(29.4)$ & $4.10 \times 10^{-53}$ \\
\hline Headache, $n(\%)$ & $22(15.6)$ & $20(37.7)$ & $14(35.9)$ & $36(100.0)$ & $23(67.6)$ & $4.88 \times 10^{-20}$ \\
\hline Migraine, $n(\%)$ & $0(0.0)$ & $0(0.0)$ & 7 (17.9) & $36(100.0)$ & $13(38.2)$ & $1.21 \times 10^{-44}$ \\
\hline Rheumatoid history, $n(\%)$ & $0(0.0)$ & $0(0.0)$ & $0(0.0)$ & $0(0.0)$ & $34(100.0)$ & $2.44 \times 10^{-64}$ \\
\hline \multicolumn{7}{|l|}{ Cardiovascular risk factors } \\
\hline High blood pressure, $n(\%)$ & $46(34.3)$ & $23(50.0)$ & $10(27.0)$ & $11(34.4)$ & $15(46.9)$ & 0.15 \\
\hline Dyslipidemia, $n(\%)$ & $58(45.3)$ & $26(53.1)$ & $16(42.1)$ & $13(43.3)$ & $15(45.5)$ & 0.86 \\
\hline Type 2 diabetes, $n$ (\%) & $23(17.8)$ & $9(18.4)$ & 7 (18.4) & $1(3.2)$ & $12(36.4)$ & 0.019 \\
\hline Smoking, $n(\%)$ & $31(22.6)$ & $10(18.9)$ & $12(30.8)$ & $6(17.1)$ & 9 (29.0) & 0.53 \\
\hline
\end{tabular}

Significant $p$ values in bold.

they develop the hearing loss in the contralateral ear (conversion from unilateral to BMD). The mean age of onset was 46 years old, comparable to BMD type 2, but it is significantly higher than it was observed in the rest of the groups (types 3, 4, or 5). BMD type 1 has no familial or autoimmune history, and patients do not have migraine, so further studies are required to investigate other concurrent comorbidities to determine contributing factors.

Bilateral MD type 2 is the second most frequently observed clinical variant, and fluctuating bilateral SNHL loss may resemble AIED, since simultaneous SNHL with vestibular symptoms can occur in 50\% patients with AIED (58). However, these patients do not have any autoimmune comorbid conditions, migraine, or familial history of MD. Interestingly, BMD type 2 patients show a vascular risk profile, since $50 \%$ of them show high blood pressure, and $53 \%$ have dyslipidemia. When we compared these frequencies with BMD type 1 , which do not differ in age or sex profile to BMD type 2 , they were not significantly different $(p=0.078)$, but further studies should assess the role of vascular risk factors in labyrinthine microcirculation in MD.

Comparing the hearing stage for the worst ear, it seems to be worse in BMD type 1 (metachronic SNHL) than in type 2 (synchronic SNLH). Since both groups do not differ for the age of onset, duration of disease, or gender distribution, we cannot determine the reason for the severe SNHL in the first ear in BMD type 1.

Bilateral MD type 3 includes all patients with familiar history of $\mathrm{MD}$, and we could subtype them in two subgroups (3a with migraine, $82 \%$, and $3 \mathrm{~b}$ BMD without migraine $18 \%$ ). These findings confirm the early description of families with MD co-segregating migraine and MD (60) and the more recent description of FMD without migraine $(2,61,62)$. According to this subtyping for FMD, there will be two types of families with $\mathrm{MD}$, with and without migraine, and they reflect the genetic heterogeneity in FMD. The families include patients with uni and $\mathrm{BMD}$, so epigenetic factors may influence uni or bilateral involvement. Most of the described families have an autosomal dominant pattern of inheritance, and the participation of several genes indicate a genetic heterogeneity in $\operatorname{FMD}(2,50)$. Although variable expressivity and incomplete penetrance was observed, we did not find cases with episodic ataxia in the families.

Bilateral MD type 4 is associated with migraine in all cases, but they do not have familial history of MD. This group may overlap with VM, and it may share common pathophysiological mechanisms (63). Patients with MD may show migraine symptoms even during the attacks of vertigo (57), and this finding could make difficult the differential diagnosis of VM and MD. Magnetic resonance imaging may be useful in the diagnostic evaluation of patients with the spectrum of VM/MD (MD with concurrent migraine or in cases VM and auditory symptoms) (64).

Bilateral MD type 5 could be considered as autoimmune $\mathrm{MD}$, since all patients have another concurrent AD. However, this group is heterogeneous and includes patients with sporadic (71\%), FMD (29\%), migraine (38\%), and both synchronic (38\%) and metachronic SNHL (62\%). Patients with BMD type 5 and migraine may have either synchronic or metachronic SNHL.

Our study has several limitations. Despite our efforts to improve phenotyping in patients with BMD, we could not classify 95 patients with BMD in any cluster, and they were excluded of the model. In fact, the largest group (BMD type 1) remains poorly characterized, since it is not associated with any particular clinical feature or etiological factor. The role of allergy in $\mathrm{MD}$ deserves more research efforts, since a high prevalence of sensitization to inhalant or food allergies have been reported in MD (65-67).

However, the recognizing of different subgroups of patients and the definition of clinical variants in BMD is not only the first step to improve the selection of patients for genetic and immunological studies but also for randomized clinical trials (RCT). Most of the RCT performed in MD, were not able to demonstrate any effects of diuretics (68) or betahistine (69) and had limited 
effectiveness for intratympanic gentamicin (70) or steroids (71), and these results could be explained by a biased selection of patients with different etiologies. Further phenotyping of these clinical variants are needed for a better understanding of the clinical heterogeneity observed in BMD.

\section{AUTHOR CONTRIBUTIONS}

LF and JL-E conceived and designed the study. AS-V, SS-P, AB-C, VP-G, HP-G, JF, EM-S, MT, GT, AG-A, RG-A, JE-S, PM, PP, JB, and JL-E collected clinical information. LF and JL-E analyzed the data and drafted the manuscript. LF, AS-V, SS-P, AB-C, VP-G, HP-G, JF, EM-S, MT, GT, AG-A, RG-A, JE-S, PM, PP, JB, and JL-E revised and approved the final version of the manuscript.

\section{ACKNOWLEDGMENTS}

We acknowledge to all members of the Meniere disease's Consortium ( $\mathrm{MeDiC}$ ), a network of clinical and research centers contributing to the study of Meniere's disease. List of participants in MeDiC: Juan Carlos Amor-Dorado (Hospital Can Misses Ibiza, Spain), IA (Complexo Hospitalario de Pontevedra, Spain),

\section{REFERENCES}

1. Lopez-Escamez JA, Carey J, Chung WH, Goebel JA, Magnusson M, Mandala M, et al. Diagnostic criteria for Meniere's disease. J Vestib Res (2015) 25(1):1-7. doi:10.3233/VES-150549

2. Requena T, Espinosa-Sanchez JM, Cabrera S, Trinidad G, Soto-Varela A, Santos-Perez S, et al. Familial clustering and genetic heterogeneity in Meniere's disease. Clin Genet (2014) 85(3):245-52. doi:10.1111/cge.12150

3. Stahle J, Friberg U, Svedberg A. Long-term progression of Meniere’s disease. Am J Otol (1989) 10(3):170-3.

4. Belinchon A,Perez-Garrigues H, Tenias JM. Evolution of symptomsin Meniere's disease. Audiol Neurootol (2012) 17(2):126-32. doi:10.1159/000331945

5. Perez-Garrigues H, Lopez-Escamez JA, Perez P, Sanz R, Orts M, Marco J, et al. Time course of episodes of definitive vertigo in Meniere's disease. Arch Otolaryngol Head Neck Surg (2008) 134(11):1149-54. doi:10.1001/ archotol.134.11.1149

6. Gazquez I, Soto-Varela A, Aran I, Santos S, Batuecas A, Trinidad G, et al. High prevalence of systemic autoimmune diseases in patients with Meniere's disease. PLoS One (2011) 6(10):e26759. doi:10.1371/journal.pone. 0026759

7. Huppert D, Strupp M, Brandt T. Long-term course of Meniere's disease revisited. Acta Otolaryngol (2010) 130(6):644-51. doi:10.3109/00016480 903382808

8. House JW, Doherty JK, Fisher LM, Derebery MJ, Berliner KI. Meniere's disease: prevalence of contralateral ear involvement. Otol Neurotol (2006) 27(3):355-61. doi:10.1097/00129492-200604000-00011

9. Lopez-Escamez JA, Viciana D, Garrido-Fernandez P. Impact of bilaterality and headache on health-related quality of life in Meniere's disease. Ann Otol Rhinol Laryngol (2009) 118(6):409-16.

10. Kitahara M, Matsubara H, Takeda T, Yazawa Y. Bilateral Meniere's disease. Adv Otorhinolaryngol (1979) 25:117-21. doi:10.1159/000402927

11. Paparella MM, Griebie MS. Bilaterality of Meniere's disease. Acta Otolaryngol (1984) 97(3-4):233-7. doi:10.3109/00016488409130984

12. Rosenberg S, Silverstein H, Flanzer J, Wanamaker H. Bilateral Meniere's disease in surgical versus nonsurgical patients. Am J Otol (1991) 12(5):336-40.

13. Palaskas CW, Dobie RA, Snyder JM. Progression of hearing loss in bilateral Meniere's disease. Laryngoscope (1988) 98(3):287-90. doi:10.1288/ 00005537-198803000-00009
AB-C (Hospital Universitario Salamanca, Spain), JB (Hospital Universitario de Gran Canaria Dr. Negrin, Las Palmas de Gran Canaria, Spain), JE-S (Hospital San Agustin Linares, Spain), JF (Hospital Miguel Servet, Zaragoza, Spain), AG-A (Hospital Universitario Vall d'Hebron, Barcelona, Spain), RG-A (Hospital Universitario Marqués de Valdecilla, Santander), JL-E (Complejo Hospitalario Universidad de Granada, Spain), Raquel Manrique Huarte, Nicolas Perez-Fernandez (Clinica Universidad de Navarra, Spain), PM (Centro Hospitalar de São João, Porto, Portugal), EM-S, Ricardo Sanz (Hospital Universitario de Getafe, Madrid, Spain), Manuel Oliva Dominguez (Hospital Costa del Sol Marbella, Spain), PP (Hospital Cabueñes, Asturias, Spain), HP-G, VP-G (Hospital La Fe, Valencia, Spain), SS-P, AS-V (Complexo Hospitalario Universitario, Santiago de Compostela, Spain), MT (Instituto Antolí Candela, Madrid, Spain), Roberto Teggi (San Raffaelle Scientific Institute, Milan, Italy), and GT (Complejo Hospitalario Badajoz, Spain).

\section{FUNDING}

This study was funded by a PI13/1242 Grant from ISCIII by FEDER funds from the EU.
14. Tokumasu K, Fujino A, Yoshio S, Hoshino I. Prognosis of Meniere's disease by conservative treatment: retrospective study on the time course of the disease. Acta Otolaryngol Suppl (1995) 519:216-8. doi:10.3109/00016489 509121908

15. Tokumasu K, Fujino A, Naganuma H, Hoshino I, Arai M. Initial symptoms and retrospective evaluation of prognosis in Meniere's disease. Acta Otolaryngol Suppl (1996) 524:43-9. doi:10.3109/00016489609124348

16. Chaves AG, Boari L, Lei Munhoz MS. The outcome of patients with Menieres disease. Braz J Otorhinolaryngol (2007) 73(3):346-50. doi:10.1016/ S1808-8694(15)30078-1

17. Balkany TJ, Sires B, Arenberg IK. Bilateral aspects of Meniere's disease: an underestimated clinical entity. Otolaryngol Clin North Am (1980) 13(4):603-9.

18. Green JD Jr, Blum DJ, Harner SG. Longitudinal followup of patients with Meniere's disease. Otolaryngol Head Neck Surg (1991) 104(6):783-8. doi:10.1177/019459989110400603

19. Stahle J, Friberg U, Svedberg A. Long-term progression of Meniere's disease. Acta Otolaryngol Suppl (1991) 485:78-83. doi:10.3109/00016489109128047

20. Havia M, Kentala E. Progression of symptoms of dizziness in Meniere's disease. Arch Otolaryngol Head Neck Surg (2004) 130(4):431-5. doi:10.1001/ archotol.130.4.431

21. Friberg U, Stahle J, Svedberg A. The natural course of Meniere's disease. Acta Otolaryngol Suppl (1984) 406:72-7.

22. Morrison AW. Predictive tests for Meniere's disease. Am JOtol (1986) 7(1):5-10.

23. Tyrrell JS, Whinney DJ, Ukoumunne OC, Fleming LE, Osborne NJ. Prevalence, associated factors, and comorbid conditions for Meniere's disease. Ear Hear (2014) 35(4):e162-9. doi:10.1097/AUD.0000000000000041

24. Kim SH, Kim JY, Lee HJ, Gi M, Kim BG, Choi JY. Autoimmunity as a candidate for the etiopathogenesis of Meniere's disease: detection of autoimmune reactions and diagnostic biomarker candidate. PLoS One (2014) 9(10):e111039. doi:10.1371/journal.pone.0111039

25. Chiarella G, Saccomanno M, Scumaci D, Gaspari M, Faniello MC, Quaresima B, et al. Proteomics in Meniere disease. J Cell Physiol (2012) 227(1):308-12. doi:10.1002/jcp.22737

26. Chiarella G, Di Domenico M, Petrolo C, Saccomanno M, Rothenberger R, Giordano A, et al. A proteomics-driven assay defines specific plasma protein signatures in different stages of Meniere's disease. J Cell Biochem (2014) 115(6):1097-100. doi:10.1002/jcb.24747 
27. Lopez-Escamez JA, Saenz-Lopez P, Gazquez I, Moreno A, Gonzalez-Oller C, Soto-Varela A, et al. Polymorphisms of CD16A and CD32 Fcgamma receptors and circulating immune complexes in Meniere's disease: a case-control study. BMC Med Genet (2011) 12:2. doi:10.1186/1471-2350-12-2

28. Brand O, Gough S, Heward J. HLA, CTLA-4 and PTPN22: the shared genetic master-key to autoimmunity? Expert Rev Mol Med (2005) 7(23):1-15. doi:10.1017/S1462399405009981

29. McCabe BF. Autoimmune sensorineural hearing loss. Ann Otol Rhinol Laryngol (1979) 88(5 Pt 1):585-9. doi:10.1177/000348947908800501

30. Amor-Dorado JC, Paco L, Martin J, Lopez-Nevot MA, Gonzalez-Gay MA. Human leukocyte antigen-DQB1 and -DRB1 associations in patients with idiopathic sudden sensorineural hearing loss from a defined population of Northwest Spain. Acta Otolaryngol (2005) 125(12):1277-82. doi:10.1080/00016480510012228

31. Harris JP, Weisman MH, Derebery JM, Espeland MA, Gantz BJ, Gulya AJ, et al. Treatment of corticosteroid-responsive autoimmune inner ear disease with methotrexate: a randomized controlled trial. JAMA (2003) 290(14):1875-83. doi:10.1001/jama.290.14.1875

32. Hughes GB, Kinney SE, Barna BP, Calabrese LH. Autoimmune reactivity in Meniere's disease: a preliminary report. Laryngoscope (1983) 93(4): 410-7.

33. Yoo TJ, Shea J Jr, Ge X, Kwon SS, Yazawa Y, Sener O, et al. Presence of autoantibodies in the sera of Meniere's disease. Ann Otol Rhinol Laryngol (2001) 110(5 Pt 1):425-9. doi:10.1177/000348940111000506

34. Fattori B, Nacci A, Dardano A, Dallan I, Grosso M, Traino C, et al. Possible association between thyroid autoimmunity and Meniere's disease. Clin Exp Immunol (2008) 152(1):28-32. doi:10.1111/j.1365-2249.2008.03595.x

35. Furuta T, Teranishi M, Uchida $Y$, Nishio N, Kato K, Otake H, et al. Association of interleukin-1 gene polymorphisms with sudden sensorineural hearing loss and Meniere's disease. Int J Immunogenet (2011) 38(3):249-54. doi:10.1111/j.1744-313X.2011.01004.x

36. Gazquez I, Moreno A, Requena T, Ohmen J, Santos-Perez S, Aran I, et al. Functional variants of MIF, INFG and TFNA genes are not associated with disease susceptibility or hearing loss progression in patients with Meniere's disease. Eur Arch Otorhinolaryngol (2013) 270(4):1521-9. doi:10.1007/ s00405-012-2268-0

37. Lopez-Escamez JA, Saenz-Lopez P, Acosta L, Moreno A, Gazquez I, PerezGarrigues $\mathrm{H}$, et al. Association of a functional polymorphism of PTPN22 encoding a lymphoid protein phosphatase in bilateral Meniere's disease. Laryngoscope (2010) 120(1):103-7. doi:10.1002/lary.20650

38. Cabrera S, Sanchez E, Requena T, Martinez-Bueno M, Benitez J, Perez N, et al. Intronic variants in the NFKB1 gene may influence hearing forecast in patients with unilateral sensorineural hearing loss in Meniere's disease. PLoS One (2014) 9(11):e112171. doi:10.1371/journal.pone.0112171

39. Gazquez I, Moreno A, Aran I, Soto-Varela A, Santos S, Perez-Garrigues H, et al. MICA-STR A.4 is associated with slower hearing loss progression in patients with Meniere's disease. Otol Neurotol (2012) 33(2):223-9. doi:10.1097/ MAO.0b013e31824296c8

40. Requena T, Gazquez I, Moreno A, Batuecas A, Aran I, Soto-Varela A, et al. Allelic variants in TLR10 gene may influence bilateral affectation and clinical course of Meniere's disease. Immunogenetics (2013) 65(5):345-55. doi:10.1007/ s00251-013-0683-Z

41. Radtke A, Lempert T, Gresty MA, Brookes GB, Bronstein AM, Neuhauser H. Migraine and Meniere's disease: is there a link? Neurology (2002) 59(11):17004. doi:10.1212/01.WNL.0000036903.22461.39

42. Lempert T, Olesen J, Furman J, Waterston J, Seemungal B, Carey J, et al. Vestibular migraine: diagnostic criteria. J Vestib Res (2012) 22(4):167-72. doi:10.3233/VES-2012-0453

43. Neff BA, Staab JP, Eggers SD, Carlson ML, Schmitt WR, Van Abel KM, et al. Auditory and vestibular symptoms and chronic subjective dizziness in patients with Meniere's disease, vestibular migraine, and Meniere's disease with concomitant vestibular migraine. Otol Neurotol (2012) 33(7):1235-44. doi:10.1097/MAO.0b013e31825d644a

44. Brown MR. The factor of heredity in labyrinthine deafness and paroxysmal vertigo; Meniere's syndrome. Ann Otol Rhinol Laryngol (1949) 58(3): 665-70.

45. Morrison AW, Bailey ME, Morrison GA. Familial Meniere's disease: clinical and genetic aspects. J Laryngol Otol (2009) 123(1):29-37. doi:10.1017/ S0022215108002788
46. Requena T, Espinosa-Sanchez JM, Lopez-Escamez JA. Genetics of dizziness: cerebellar and vestibular disorders. Curr Opin Neurol (2014) 27(1):98-104. doi:10.1097/WCO.0000000000000053

47. Frejo L, Giegling I, Teggi R, Lopez-Escamez JA, Rujescu D. Genetics of vestibular disorders: pathophysiological insights. J Neurol (2016) 263(Suppl 1):45-53. doi:10.1007/s00415-015-7988-9

48. Lee JM, Kim MJ, Jung J, Kim HJ, Seo YJ, Kim SH. Genetic aspects and clinical characteristics of familial Meniere's disease in a South Korean population. Laryngoscope (2015) 125(9):2175-80. doi:10.1002/lary.25207

49. Ohmen JD, White CH, Li X, Wang J, Fisher LM, Zhang H, et al. Genetic evidence for an ethnic diversity in the susceptibility to Meniere's disease. Otol Neurotol (2013) 34(7):1336-41. doi:10.1097/MAO.0b013e3182868818

50. Requena T, Cabrera S, Martin-Sierra C, Price SD, Lysakowski A, LopezEscamez JA. Identification of two novel mutations in FAM136A and DTNA genes in autosomal-dominant familial Meniere's disease. Hum Mol Genet (2015) 24(4):1119-26. doi:10.1093/hmg/ddu524

51. Committee on Hearing and Equilibrium guidelines for the diagnosis and evaluation of therapy in Meniere's disease. American Academy of Otolaryngology-Head and Neck Foundation, Inc. Otolaryngol Head Neck Surg (1995) 113(3):181-5. doi:10.1016/S0194-5998(95)70102-8

52. Belinchon A, Perez-Garrigues H, Tenias JM, Lopez A. Hearing assessment in Meniere's disease. Laryngoscope (2011) 121(3):622-6. doi:10.1002/lary.21335

53. Tyler R, Coelho C, Tao P, Ji H, Noble W, Gehringer A, et al. Identifying tinnitus subgroups with cluster analysis. Am J Audiol (2008) 17(2):S176-84. doi:10.1044/1059-0889(2008/07-0044)

54. Nabi S, Parnes LS. Bilateral Meniere's disease. Curr Opin Otolaryngol Head Neck Surg (2009) 17(5):356-62. doi:10.1097/MOO.0b013e3283304cb3

55. Morita N, Kariya S, Farajzadeh Deroee A, Cureoglu S, Nomiya S, Nomiya R, et al. Membranous labyrinth volumes in normal ears and Meniere disease: a three-dimensional reconstruction study. Laryngoscope (2009) 119(11): 2216-20. doi:10.1002/lary.20723

56. Nonoyama $H$, Tanigawa $T$, Tamaki $T$, Tanaka H, Yamamuro O, Ueda $H$. Evidence for bilateral endolymphatic hydrops in ipsilateral delayed endolymphatic hydrops: preliminary results from examination of five cases. Acta Otolaryngol (2014) 134(3):221-6. doi:10.3109/00016489.2013.850741

57. Lopez-Escamez JA, Dlugaiczyk J, Jacobs J, Lempert T, Teggi R, von Brevern $\mathrm{M}$, et al. Accompanying symptoms overlap during attacks in Meniere's disease and vestibular migraine. Front Neurol (2014) 5:265. doi:10.3389/fneur. 2014.00265

58. Pathak S, Hatam LJ, Bonagura V, Vambutas A. Innate immune recognition of molds and homology to the inner ear protein, cochlin, in patients with autoimmune inner ear disease. J Clin Immunol (2013) 33(7):1204-15. doi:10.1007/ s10875-013-9926-x

59. Eisen MD, Niparko JK. Chapter 31 - autoimmune inner ear disease. In: Eggers SDZ, Zee DS, editors. Handbook of Clinical Neurophysiology (Vol. 9), Elsevier (2010). p. 428-32.

60. Oliveira CA, Ferrari I, Messias CI. Occurrence of familial Meniere's syndrome and migraine in Brasilia. Ann Otol Rhinol Laryngol (2002) 111(3 Pt 1):229-36. doi:10.1177/000348940211100307

61. Arweiler-Harbeck D, Horsthemke B, Jahnke K, Hennies HC. Genetic aspects of familial Meniere's disease. Otol Neurotol (2011) 32(4):695-700. doi:10.1097/ MAO.0b013e318216074a

62. Hietikko E, Kotimaki J, Kentala E, Klockars T, Sorri M, Mannikko M. Finnish familial Meniere disease is not linked to chromosome 12p12.3, and anticipation and cosegregation with migraine are not common findings. Genet Med (2011) 13(5):415-20. doi:10.1097/GIM.0b013e3182091a41

63. Espinosa-Sanchez JM, Lopez-Escamez JA. New Insights into pathophysiology of vestibular migraine. Front Neurol (2015) 6:12. doi:10.3389/fneur.2015.00012

64. Gurkov R, Kantner C, Strupp M, Flatz W, Krause E, Ertl-Wagner B. Endolymphatic hydrops in patients with vestibular migraine and auditory symptoms. Eur Arch Otorhinolaryngol (2014) 271(10):2661-7. doi:10.1007/ s00405-013-2751-2

65. Di Berardino F, Cesarani A. Gluten sensitivity in Meniere's disease. Laryngoscope (2012) 122(3):700-2. doi:10.1002/lary.22492

66. Derebery MJ.Allergic and immunologic features of Meniere's disease. Otolaryngol Clin North Am (2011) 44(3):655-66, ix. doi:10.1016/j.otc.2011. 03.004

67. Powers WH. Allergic factors in Meniere's disease. Trans Am Acad Ophthalmol Otolaryngol (1973) 77(1):ORL22-9. 
68. Thirlwall AS, Kundu S. Diuretics for Meniere's disease or syndrome. Cochrane Database Syst Rev (2006) (3):CD003599. doi:10.1002/14651858.CD003599. pub2

69. Adrion C, Fischer CS, Wagner J, Gurkov R, Mansmann U, Strupp M, et al. Efficacy and safety of betahistine treatment in patients with Meniere's disease: primary results of a long term, multicentre, double blind, randomised, placebo controlled, dose defining trial (BEMED trial). BMJ (2016) 352:h6816. doi:10.1136/bmj.h6816

70. Pullens B, van Benthem PP. Intratympanic gentamicin for Meniere's disease or syndrome. Cochrane Database Syst Rev (2011) (3):CD008234. doi:10.1002/14651858.CD008234.pub2

71. Phillips JS, Westerberg B. Intratympanic steroids for Meniere's disease or syndrome. Cochrane Database Syst Rev (2011) (7):CD008514. doi:10.1002/14651858.CD008514.pub2
Conflict of Interest Statement: The authors declare that the research was conducted in the absence of any commercial or financial relationships that could be construed as a potential conflict of interest.

Copyright $\odot 2016$ Frejo, Soto-Varela, Santos-Perez, Aran, Batuecas-Caletrio, PerezGuillen, Perez-Garrigues, Fraile, Martin-Sanz, Tapia, Trinidad, García-Arumi, González-Aguado, Espinosa-Sanchez, Marques, Perez, Benitez and Lopez-Escamez On Behalf of the Meniere's Disease Consortium (MeDiC). This is an open-access article distributed under the terms of the Creative Commons Attribution License (CC $B Y$ ). The use, distribution or reproduction in other forums is permitted, provided the original author(s) or licensor are credited and that the original publication in this journal is cited, in accordance with accepted academic practice. No use, distribution or reproduction is permitted which does not comply with these terms. 